\title{
Pump Body Casting Process Design and Optimization Based on Numerical Simulation
}

\author{
Zhi-Qiang Zhou and Bing-Rong Zhang
}

\begin{abstract}
Aimed at the problems of complex structure and uneven wall thickness of a aluminum pump, two kinds of pouring system for aluminum pump body were designed, being the traditional gravity and low-pressure castings respectively. Based on the simulation results of these two casting processes of the pump body, the location and types of casting defects were analyzed, being helpful to select the most suitable casting process for the pump body. In this paper, the low pressure casting process was applied with suitable parameters based on the simulation results and added water cooling. Finally, the qualified pump body casting has been obtained and put into production.
\end{abstract}

Index Terms-Low pressure (die) casting, pump body, ProCAST.

\section{INTRODUCTION}

The traditional casting production depends mainly on the practical experience, especially for the complex parts [1], which need to repeatedly modify the casting structure or the use of other casting process options, often need to spend more pre-human and material resources[2], [3].With the rapid development of computer technology in the foundry industry and its widespread application, casting CAE software is used to simulate the process of filling and casting, the temperature gradient of the casting, the solidification process of the casting, and then the simulation results are used to determine the better casting process, which may shorten the product trial cycle, reduce production costs and improve material utilization. Based on the CAE casting technology, ProCAST software was used to simulate the pump body for the gravity and low-pressure casting processes in order to provide reference for the production of pump body and elimination of the defects [4]-[9].

\section{Model Design}

The pump model was designed and modified by using UG three-dimensional modeling software. Fig. 1, Fig. 2, Fig. 3 shows the injection pump casting three-dimensional modeling. Casting size of $132 \mathrm{~mm} \times 111 \mathrm{~mm} \times 147 \mathrm{~mm}$, the

Manuscript received August 30, 2018; revised January 20, 2019. This work was supported by Fund Project: Natural Science Foundation of Shandong Province (ZR2016EEM48); Major Science and Technology Project of Shandong Province (2015ZDZX03004).

Zhi-Qiang Zhou is with the School of Mechanical \&Automotive Engineering, Qi Lu University of Technology (Shandong Academy of Sciences), Jinan 250300, China (e-mail: zzq6688@qq.com).

Bing-Rong Zhang is with the Mechanical and Automotive Engineering School of Qi Lu University of Technology (Shandong Academy of Sciences), Jinan, Shandong Province, 250001, China (Corresponding author; e-mail: brzit@aliyun.com). center of the casting has a diameter of $56 \mathrm{~mm}$, a depth of $80 \mathrm{~mm}$ hole, the other connection hole diameter $22 \mathrm{~mm}$, hole depth $31 \mathrm{~mm}$, castings total weight $1.6 \mathrm{~kg}$. Pump material is the ZL101 alloy, castings set the local area of chiller in order to achieve the order of solidification. Due to the presence of circular holes and grooves in the pump body, it is necessary to carry out side-pumping. According to the structure of the casting design gravity casting mold and low pressure casting mold modeling.

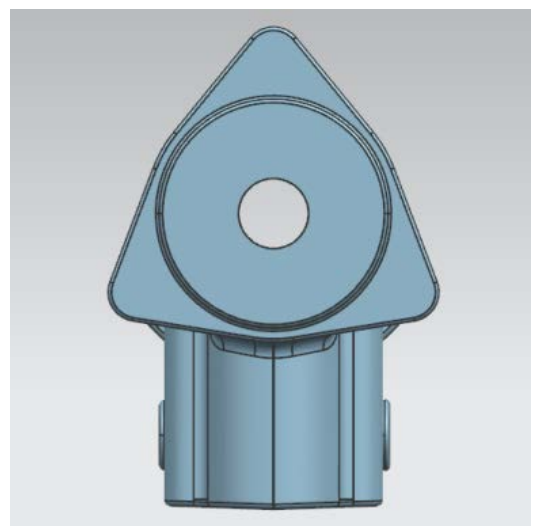

Fig. 1. Pump body structure.

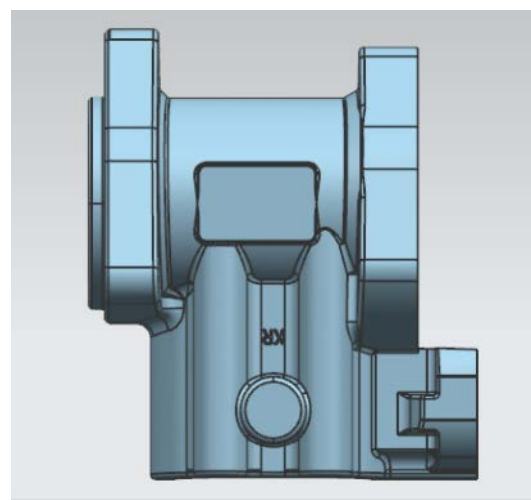

Fig. 2. Pump body structure.

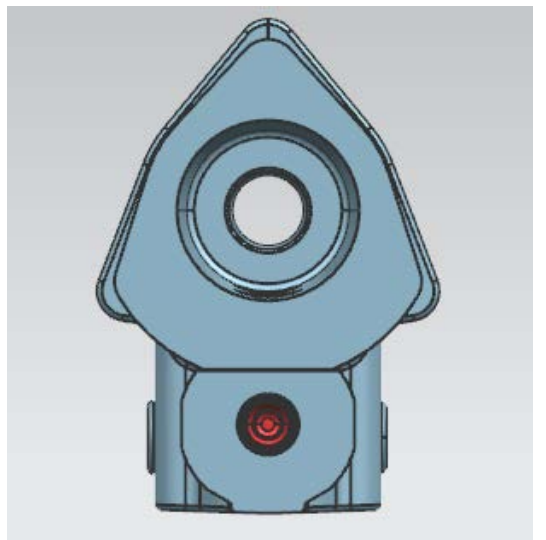

Fig. 3. Pump body structure. 


\section{Simulation Process And Result Analysis}

\section{A. ProCAST Simulation Model Pre-treatment Process}

The finite element mesh must be defined before the simulation is performed. The meshing is done by the Mesh CAST module in Pro CAST. Use UG to finish the 3D model and save it as igs format file, then open the format in the Mesh CAST module and draw the surface mesh, merge the common surface and check the surface mesh after checking the correctness, draw the model three-dimensional grid. The finer the mesh, the more accurate the result. After completing face meshing and checking the correct, body grid division was conducted. Fig. 4 shows the finite element model of the pump body casting under the gravity casting process and Fig. 5 shows the finite element model of the pump body casting under the low pressure casting process.

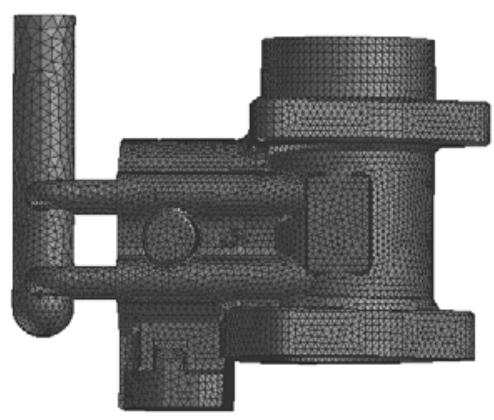

Fig. 4. Finite element model of the pump body casting under the gravity casting process.

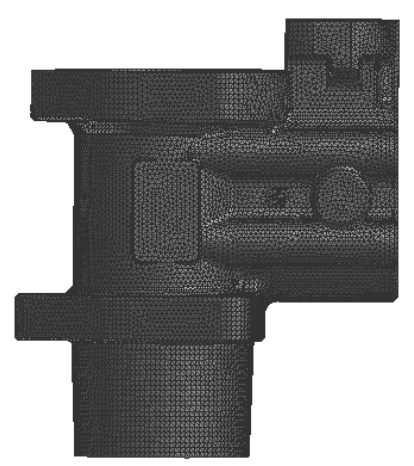

Fig. 5. Finite element model of the pump body casting under the gravity casting process.

\section{B. Pro CAST Simulation and Parameter Setting of Casting Processes}

Casting process parameters were set through the Pro CAST software CAST module, thermal properties of the material and casting parameters are:

1) Assuming that there is no gap between the casting and the mold, there is only one way of heat conduction between the molten metal and the mold, and only the convection heat transfer to the air is taken into consideration on the outer surface of the mold. The pump mold, H13 die steel, in the simulation process is considered virtual mold, while the liquids temperature and solidus temperature are $610{ }^{\circ} \mathrm{C}$ and $502{ }^{\circ} \mathrm{C}$ respectively.
2) The initial temperature of chiller and casting mold is the same, which is $200{ }^{\circ} \mathrm{C}$.

3) The definition of thermal conductivity. The conductivity of castings and molds, castings and cold iron can use metal-metal conductivity of which the Pro CAST equipped itself, heat transfer coefficient set $\mathrm{H}=3000$, the heat exchange mode of mold itself is set to air-cooled.

4) For the low pressure casting process, the mold preheating temperature, pouring temperature and filling time are dominant factors on the molten metal cavity filling capacity and casting quality. Thus the Orthogonal test is designed by using a variety of factors at different levels of coupling. For the comparison of experimental data, the parameters of gravity casting process and low pressure casting process are set the same.

\section{Casting Process Simulation Analysis}

Through the orthogonal test simulation results, the final aluminum alloy liquid temperature is $700{ }^{\circ} \mathrm{C}$, mold temperature is $200{ }^{\circ} \mathrm{C}$. Calculated data with Solver, calculated results of the type, location, and topography of the defect after casting solidification are shown in the View module in Pro CAST software.

From Fig. 6, Fig. 7 and Fig. 8, it can be seen that the molten aluminum filling is not stable when filling 30\%, 60\%, $90 \%$ of the gravity casting, and the pouring, impacting and spattering of molten aluminum occur during casting filling. The low-pressure castings have no such problems. Different colors on the left side of the image correspond to different aluminum liquid temperatures, and $700{ }^{\circ}$ Crepresents the initial liquid temperature of molten aluminum, decreasing proportionally from $700{ }^{\circ} \mathrm{C}$ to $20^{\circ} \mathrm{C}$.

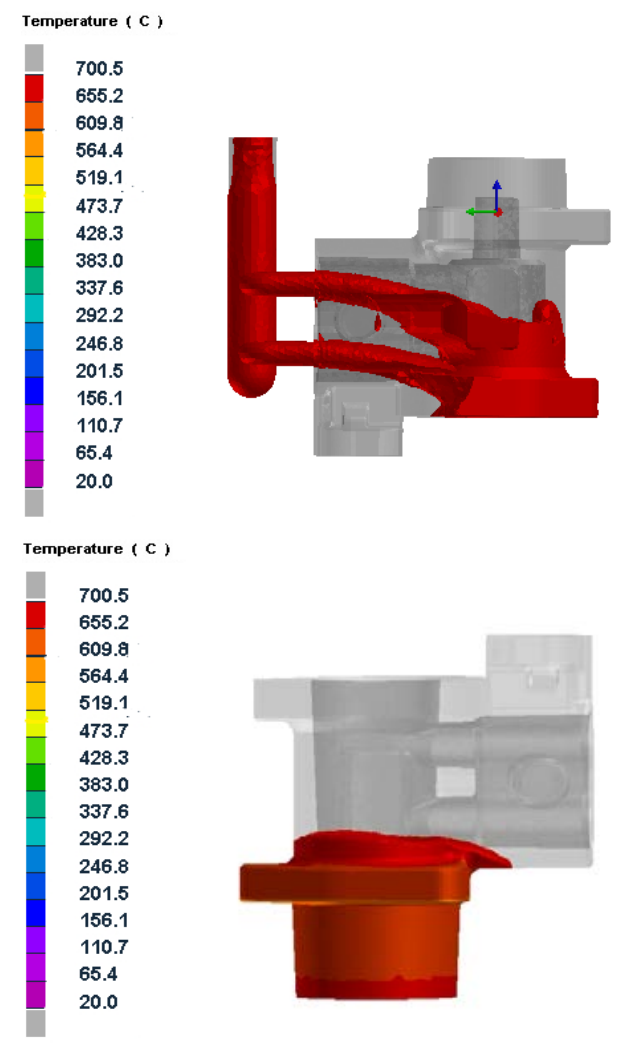

Fig. 6. Mold filling aluminum 30\% solution image. 


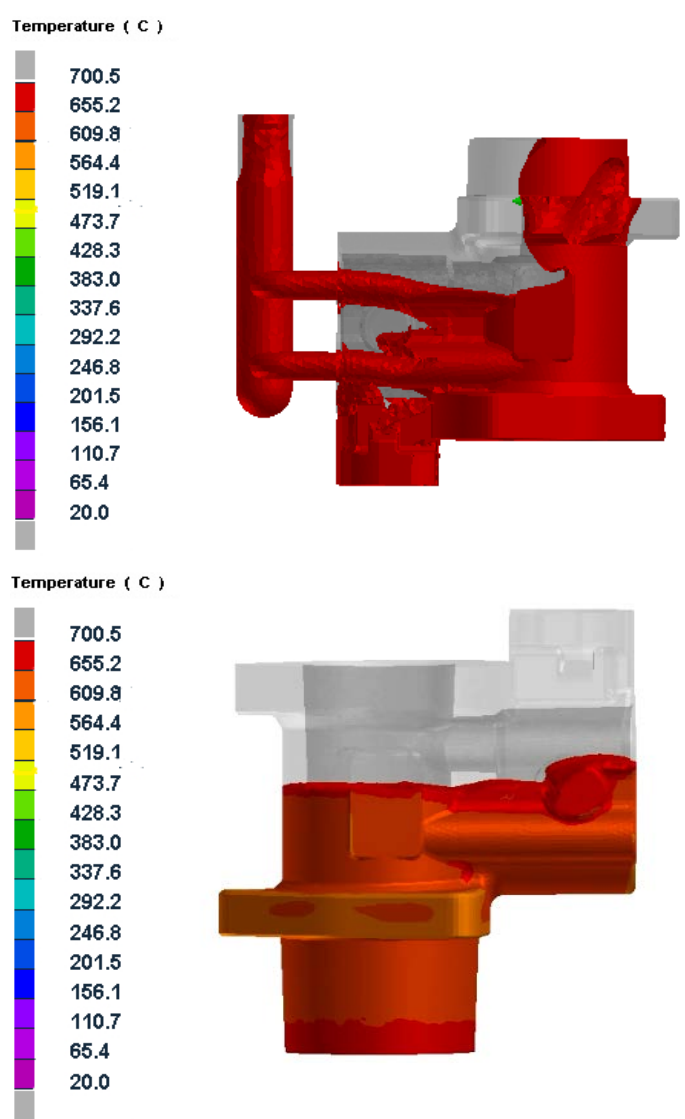

Fig. 7. Mold filling aluminum $60 \%$ solution image.

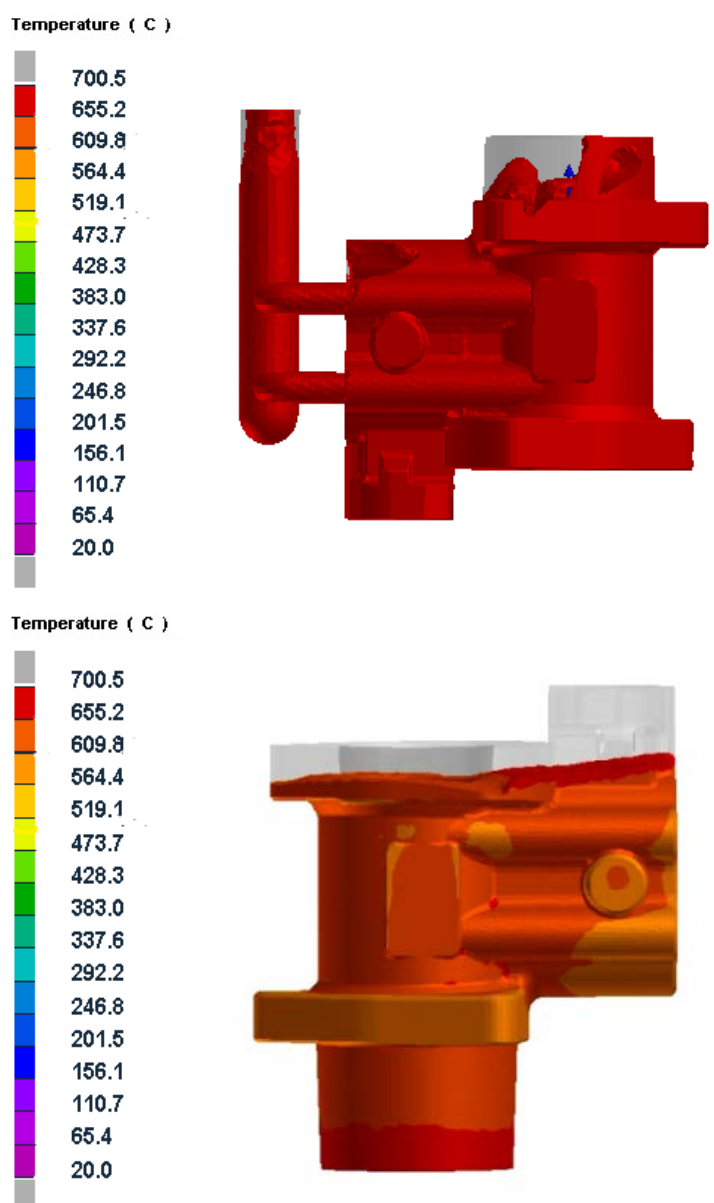

Fig. 8. Mold filling aluminum 90\% solution image.

As shown in Fig. 9, there are three shrinkage results for the gravity casting process. The low-pressure casting has two shrinkage, and the location of the shrinkage are in the left side of the chiller. The initial analysis of the thickness of the casting section can be that the irregular surface roughness hole formed at hot section or the axis of the final solidification of the place, where coarse grains, often with dendrites. As the liquid shrinkage and solidification shrinkage is much larger than the solid-state shrinkage in the cooling and solidification process, the final solidification of the casting cannot be obtained due to the addition of molten aluminum, the shrinkage formed.
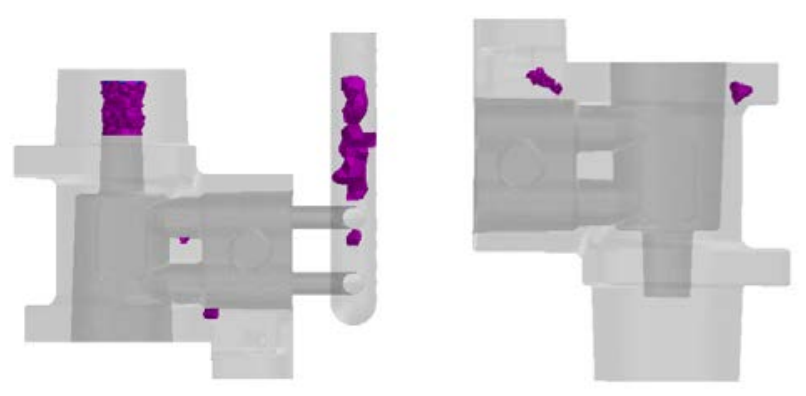

Fig. 9. Schematic diagram of shrinkage porosity and porosity in castings.

Based on the high-pressure performance of injection pump itself and simulation results, combined with low-pressure casting process can guarantee a smooth filling of liquid metal. The tumbling, impact and splashing phenomena can be reduced or avoided in the low pressure casting process, and oxide slag was less formed, thereby the casting defects were reduced casting quality was improved accordingly. Results shows low-pressure casting process prototype, large gate diameter, and water-cooled device added at the pumping core position would produce good performed casting.

\section{Production Validation}

The parameters are optimized according to the simulation results and production is carried out. As shown in Fig. 10 and Fig 11, the castings manufactured by different processes are sliced from the same position, and also through the position of defects in the Pro CAST simulation results, after spraying and placing cold iron, the position of the circle mark in the figure clearly shows the gravity metal. There are still shrinkage and shrinkage defects in the thick part of the cast part. A similar phenomenon occurs in very few low-pressure castings, further verifying the reliability of the casting system and casting parameters obtained through software simulation.
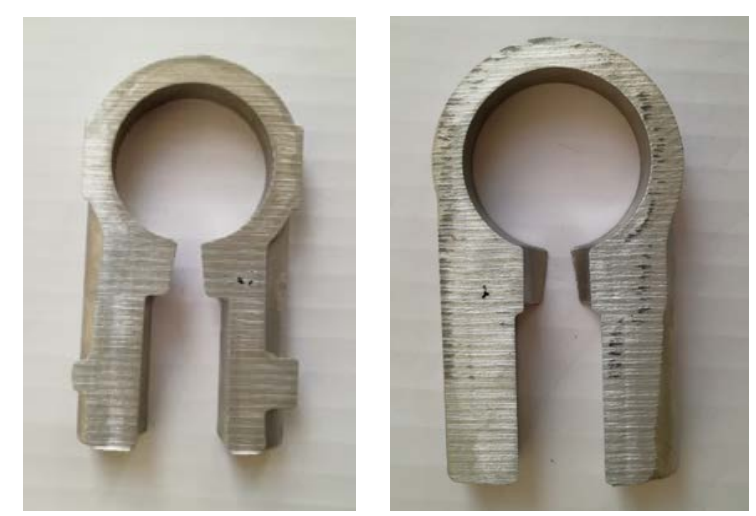

Fig. 10. Partial sectioning of castings in gravity casting process. 


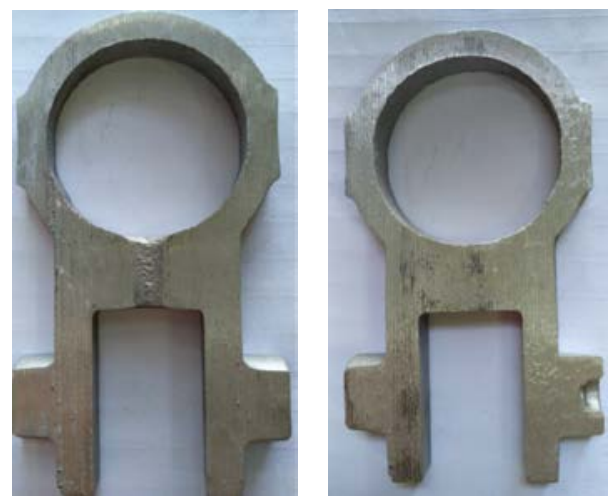

Fig. 11. Partial sectioning of castings in low pressure casting process.

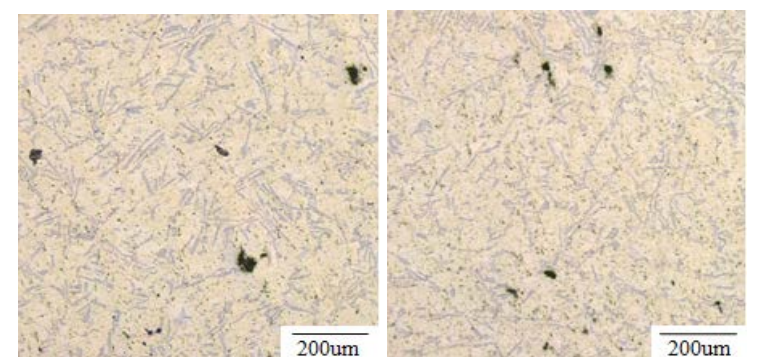

Fig. 12. Metallographic diagram of microstructure of castings in gravity casting process.
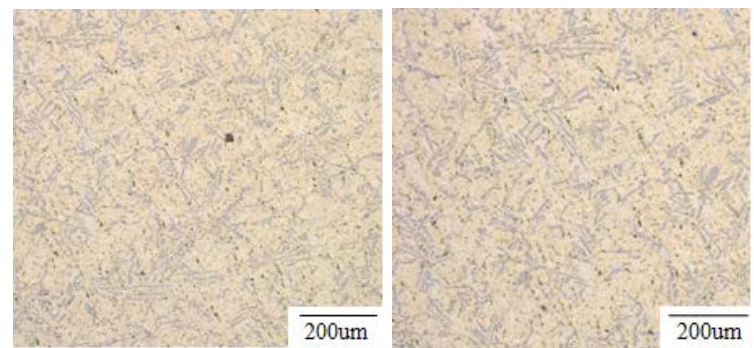

Fig.13. Metallographic diagram of microstructure of castings in low pressure casting process.

As shown in Fig. 12 and Fig. 13, the microscopic phase is observed at the same position under the two casting processes, and the defects such as shrinkage slag inclusion in the low pressure casting process are significantly less, and the microstructure is dense. The low pressure casting process is more suitable for the production of the pump body. At the same time, it shows that the low-pressure casting is stable and the aluminum liquid is solidified and filled, and the grain growth is good.

\section{CONCLUSION}

1) Pro CAST software was used to simulate the process of filling and solidification of castings. The dynamic filling and solidification process of castings during filling and solidification were obtained, and the possible defects in the castings were predicted. According to the result, a suitable casting process was selected, and at the same time, a targeted optimization scheme was proposed.

2) According to the pump low-pressure casting process of the program, the molten aluminum flow in the filling process is more gentle, so as to avoid the splashing of the molten metal and the defects of gas trap. So that a large number of pump casting thick shrinkage cavity eliminate entirely, improving production efficiency. Finally, the proposal is used for actual production

\section{REFERENCES}

[1] S. Lu, F. Xiao, S. Zhang, Y. Mao, and B. Liao, "Simulation study on the centrifugal casting wet-type cylinderliner based on ProCAST," Applied Thermal Engineering, vol. 73, pp. 512-521, 2014.

[2] ESI Software Inc., ProCAST User's Manual \& Technical Reference, Annapolis, America: ESI Software Inc., 2007.

[3] M. Brůna, D. Bolibruchová, and R. Pastirčák, "Numerical simulation of porosity for AI based alloys," Procedia Engineering, vol. 177, pp. 488-495, 2017.

[4] H. F. Lu, R. F. Chen, Y. H. Zhao, L. Wu, Z. L. Li, and H. Yang, "Numerical simulation and process optimization of aluminum alloy connecting rod based on ProCAST," Advanced Materials Research, vol. 712, 2013.

[5] T. Liang, Y. H. Qu, X. F. Liu, F. Wang, and M. H. Zhang, "Simulation of filling and solidification processes of rump pan by ProCAST," Advanced Materials Research, vol. 2605, no. 785, 2013.

[6] H. Wu, H. M. Shi, H. F. Liu, and Z. J. Xia, "Numerical simulation of flow field and temperature field on aluminium alloy engine cylinder in casting process,” Materials Science Forum, vol. 1534, no. 704, 2012.

[7] ESI Group, "ESI Announces the Release of ProCAST and QuikCASTVersion 2009," Computer Weekly News, 2009.

[8] Y. Dong, X. M. Fan, and B. Liu, "Numerical simulation and technology optimization of rear oil seal bearing die castings based on ProCAST," Advanced Materials Research, vol. 1165, no. 189, 2011.

[9] H. W. Liu, F. Feng, C. L. Yan, and X. F. Zheng, "Computer simulation of the filling process of air intake hood based on ProCAST," Advanced Materials Research, vol. 1684, no. 487, 2012.

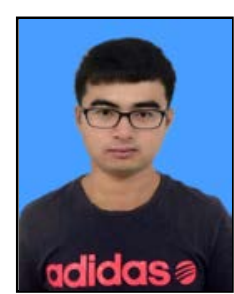

Zhou Zhiqiang was born in Shandong Province in February 1992. He obtained a bachelor's degree in mechanical engineering from Jinan University, China in 2014. Now as an under postgraduate, he is studying for Master degree at Qilu University of Technology in Jinan, China. He participates in Major Project Research of Shandong Province (2015ZDZX03004). He has been working as an intern in Shandong Tailai Aluminum Foundry Technology Co., Ltd. Current research interests are casting simulation and mold design etc.

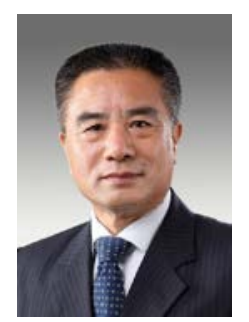

Zhang Bingrong was born in Shandong Province in 1958. He received his Ph.D. degree in materials engineering from Turin Polytechnic University, Italy in 1998. His major field of study is materials science and engineering.

He worked as senior engineer and project manager for Teksid Aluminum Co., Ltd (FIAT group, Italy) from 1997 to 2004. He served as general manager for Wuhu Trinity Technology Co., Ltd from 2005 to 2007 and chief engineer for Chery Automotive Company (China) from 2008 to 2013. Today he is Full Professor at Mechanical and Automotive Engineering School of Qilu University of Technology in Jinan, Shandong Province. And he has been the vice president of Foundry Society of Anhui Province, China since 2007. Current research interests are advanced aluminum alloys for automotive, aircraft, rail transit applications and castings development. 